\title{
ANTIOXIDANT AND CYTOTOXIC ACTIVITIES OF ‘AÇAÍ’ (Euterpe precatoria Mart.)
}

\author{
Ana Lúcia Q. A. Galotta \\ Departamento de Química, Instituto de Ciências Exatas, Universidade Federal do Amazonas, Av. Rodrigo Otávio Jordão Ramos, \\ 3000, 69000-000 Manaus - AM, Brasil \\ Maria Amélia D. Boaventura* e Luciana A. R. S. Lima \\ Departamento de Química, Instituto de Ciências Exatas, Universidade Federal de Minas Gerais, Av. Antônio Carlos, 6627, \\ 31270-970 Belo Horizonte - MG, Brasil
}

Recebido em 30/8/07; aceito em 29/2/08; publicado na web em 26/8/08

\begin{abstract}
Decoction of roots of the Amazonian palm açaí (Euterpe precatoria Mart.) is widely used by Brazilian and Peruvian people as an anti-inflammatory, to heal kidney and liver diseases and against snake bites. In this study, the antioxidant activity of extracts and flavonoids (quercetin, catechin, epicatechin, rutin and astilbin) isolated from roots and leaf stalks of $E$. precatoria was investigated using $\beta$-carotene in TLC plates and DPPH radical scavenging in a spectrophotometric bioassay. All extracts and flavonoids showed activity. Also, the cytotoxic activity of these extracts was evaluated by the brine shrimp (Artemia salina) larvicide bioassay and was lower than that of lapachol, used as control. The presence of flavonoids and sitosterol-3- $O-\beta$ - $D$-glucopyranoside in the extracts can justify the use of the plant in traditional medicine.
\end{abstract}

Keywords: açaí; Euterpe precatoria; antioxidant activity.

\section{INTRODUCTION}

Besides the endogenous mechanisms of living organisms to fight free radicals that play a crucial role in the development of various diseases (coronary artery diseases, cancer, arteriosclerosis, Alzheimer), antioxidants from exogenous sources as plant-derived agents may help in their prevention. Plants contain a wide variety of compounds possessing potent antioxidant activity and determination of the natural antioxidant compounds of plant extracts is important in development of new drugs for antioxidant therapy.

Euterpe precatoria Mart. (Arecaceae), known popularly as 'açaí or açaí-de-terra-firme', occurs in Central and Western Amazonia in areas without permanent flooding (Euterpe olearaceae, also known as 'açaí', occurs in areas with permanent flooding). The heart of the tree is used as food, whereas the pulp of fruits is macerated to give a thick, dark purple liquid, locally called 'açaî' or 'vinho de açaí' (açaí's wine, although it is not a fermented or distilled beverage).

Decoction or syrup of roots and leaf stalks of E. precatoria are used by people of the Brazilian and Peruvian Amazonian region against snake bites, muscular and chest pains, as a general tonic for anemia, in diabetes, kidney and liver diseases. ${ }^{1,2}$ Aqueous and methanolic extracts of the dried roots showed anti-inflammatory properties. $^{2}$

To our knowledge only two papers have been reported in the literature on the chemical constituents of E. precatoria. The first work presented an antiplasmodial lignane and $p$-hydroxybenzoic acid, obtained from roots ${ }^{3}$ and the second revealed the presence of cytotoxic triterpenes, steroids and also p-hydroxybenzoic acid, isolated from hexane, ethyl acetate and methanolic extracts of roots and leaf stalks. ${ }^{4}$

In this work we describe the antioxidant activity evaluation of ethanol extracts from roots and leaf stalks of E. precatoria and of five flavonoids (quercetin, catechin, epicatechin, rutin and astilbin) isolated from them, aiming at a correlation of this activity with popu-

\footnotetext{
*e-mail: dianadb@netuno.lcc.ufmg.br
}

lar uses of the plant. The antioxidant activity was investigated using $\beta$-carotene in TLC plates $^{5}$ and 1,1-diphenyl-2-picrylhydrazyl (DPPH) radical scavenging spectrophotometric bioassay. ${ }^{6}$ The potential cytotoxic effects of these extracts were evaluated by the brine shrimp ( $A$. salina) larvicide bioassay. ${ }^{7}$ Beside the flavonoids, sitosterol-3- $O-\beta-D-$ glucopyranoside was also isolated from root extract.

The structures of the pure isolated compounds were determined based on ${ }^{1} \mathrm{H}$ and ${ }^{13} \mathrm{C}$ NMR data (1D and 2D), by comparison of these spectral data with those reported in the literature and with those obtained from the authentic samples.

\section{EXPERIMENTAL}

\section{General}

Nuclear Magnetic Resonance (NMR) spectra were recorded in $\mathrm{CD}_{3} \mathrm{OD}, \mathrm{D}_{2} \mathrm{O}, \mathrm{DMSO}-\mathrm{d}_{6}, \mathrm{CDCl}_{3} /$ pyridine- $\mathrm{d}_{5}$, at room temperature, on a Bruker Avance DRX $400 \mathrm{MHz}$ spectrometer. The two-dimensional (2D) NMR experiments were HMQC (Heteronuclear Multiple-Quantum Correlation) and NOESY (Nuclear Overhauser Effect Spectroscopy). Silica gel Merck 100-200 and 200-425 mesh were used for column chromatography and silica gel Merck $60 \mathrm{G}$ was used for thin layer chromatography. Sephadex LH-20 was purchased from Sigma. Polyamide was purchased from Macherey Nagel. Solvents PA and HPLC grade were purchased from Vetec (Brazil) and Sigma Chemicals Co (St. Louis, USA), respectively. BHT (2,6-di-tert-butyl-4-methylphenol), DPPH $(\alpha, \alpha-$ diphenyl- $\beta$-picrylhydrazyl), $\beta$-carotene, catechin and epicatechin were also purchased from Sigma. Lapachol was purchased from Aldrich.

\section{Plant material}

Dried roots and leaf stalks of Euterpe precatoria were collected in the Mini Campus of Amazonas Federal University, Manaus, Brazil in September 2000. Voucher specimen is kept in the Herbarium of Instituto de Ciências Biológicas da Universidade Federal do Amazonas (HUAM), Brazil (no. 7297). 


\section{Fractionation and isolation}

Powdered roots $(2.3 \mathrm{~kg})$ and leaf stalks $(1.2 \mathrm{~kg})$ of E. precatoria were extracted with ethanol at room temperature and the ethanol was removed under vacuum using a rotatory evaporator. The ethanol root extract, ERE, $(199.0 \mathrm{~g})$ was partitioned with $350.0 \mathrm{~mL}$ of n-butanol and the $\mathrm{n}-\mathrm{BuOH}$ extract $(150.5 \mathrm{~g})$ was then chromatographed over polyamide column, eluted with water, ethanol and ethyl acetate with decreasing polarities. Eleven groups of fractions were obtained; G-6 $(2.10 \mathrm{~g})$ was submitted to chromatography over silica gel, employing gradient elution of dichloromethane/acetone/water (12:12:1, 10:14:1, $8: 16: 1)$ and acetone/water $(9: 1,7: 3,1: 1)$. The fractions were grouped in 8 subgroups: G6-3 $(58.7 \mathrm{mg})$ and G6-4 $(79.6 \mathrm{mg})$ were chromatographed over Sephadex LH-20 column, eluted with ethanol and 10.3 $\mathrm{mg}$ of $(+)$ catechin $^{8}(\mathbf{1})$ and $5.9 \mathrm{mg}$ of (-) epicatechin ${ }^{8}(\mathbf{2})$ were isolated, respectively. From G-7 (207.3 mg), $85.7 \mathrm{mg}$ of sitosterol-3- $O-\beta-D-$ glucopyranoside ${ }^{9}(3)$ precipitated and $7.2 \mathrm{mg}$ of $\operatorname{astilbin~}^{10}(\mathbf{4})$ were obtained, by chromatography over silica gel (eluted with dichloromethane/ acetone/water12:12:1, 10:14:1, 10:15:1, 9:16:, 6:18:1 and 6:18:3), and purified over Sephadex LH-20 (eluent: ethanol).

A mixture of 1:1 methanol/chloroform was added to the leaf stalk ethanol extract, LSE, $(25.6 \mathrm{~g})$ and the residue obtained from the soluble fraction, after concentration, LSE-2 (15.2 g), was fractionated on polyamide column (eluents: water, ethanol and ethyl acetate, with decreasing polarities) and twelve group of fractions were obtained. From G-4 (0.24 g), by chromatography over Sephadex LH-20 (methanol as eluent), $12.5 \mathrm{mg}$ of $\operatorname{rutin}^{11}(\mathbf{5})$ was isolated. From G-6 (0.81 g), by chromatography over Sephadex LH-20 (chloroform/methanol 1:1 as eluent), $250.0 \mathrm{mg}$ of quercetin ${ }^{11}(\mathbf{6})$ was obtained.

(+)-Catechin ${ }^{8}(\mathbf{1}):[\alpha]_{\mathrm{D}}=+8.0\left(\mathrm{CH}_{3} \mathrm{OH}, c 0.23\right) .{ }^{1} \mathrm{HNMR}(400 \mathrm{MHz}$, $\left.\mathrm{CD}_{3} \mathrm{OD}, \delta\right) 4.57$ (d, J=7.5 Hz, H-2); 3.97 (m, H-3); 2.51 (dd, $J=16.1$ and $8.1 \mathrm{~Hz}, \mathrm{H}-4_{\mathrm{ax}}$ ); 2.85 (dd, $J=16.1$ and $5.4 \mathrm{~Hz}, \mathrm{H}-4_{\mathrm{eg}}$ ); 5.93 (d, $J=2.3 \mathrm{~Hz}$, H-6); 5.86 (d, $J=2.3 \mathrm{~Hz}, \mathrm{H}-8) ; 6.84$ (d, $\left.J=2.0 \mathrm{~Hz}, \mathrm{H}-2^{\prime}\right) ; 6.76$ (d, $J=8.1$ $\mathrm{Hz}, \mathrm{H}-5$ '); 6.72 (dd, $J=8.1$ and $2.0 \mathrm{~Hz}, \mathrm{H}-6$ '). ${ }^{13} \mathrm{C}$ NMR (100 MHz, CD $\mathrm{OD}, \delta$ ): 83.0 (C-2); 69.0 (C-3); 28.6 (C-4); 157.7 (C-5); 96.5 (C-6); 157.9 (C-7); 95.7 (C-8); 157,1 (C-9); 101.1 (C-10); 132.4 (C-1'); 115.4 (C-2'); 146.4 (C-3'); 146.4 (C-4'); 116.3 (C-5'); 120.2 (C-6').

(-)-Epicatechin ${ }^{8}(2):[\alpha]_{\mathrm{D}}=-29.6\left(\mathrm{CH}_{3} \mathrm{OH}, c 0.23\right) .{ }^{1} \mathrm{H}$ NMR $(400$ $\left.\mathrm{MHz}, \mathrm{CD}_{3} \mathrm{OD}, \delta\right) 4.80$ (br. s, H-2); 4.19 (br. s, H-3); 2.74 (dd, J=16.8 and $2.9 \mathrm{~Hz}, \mathrm{H}-4_{\mathrm{ax}}$ ); 2.86 (dd, $J=16.8$ and $4.3 \mathrm{~Hz}, \mathrm{H}-4_{\mathrm{eq}}$ ); 5.95 (d, $J=2.3 \mathrm{~Hz}, \mathrm{H}-6) ; 5.92$ (d, $J=2.3 \mathrm{~Hz}, \mathrm{H}-8) ; 6.98$ (d, $J=1.8^{\mathrm{eq}} \mathrm{Hz}, \mathrm{H}-2^{\prime}$ ); 6.76 (d, $J=8.2, \mathrm{H}-5$ '); 6.80 (dd, $J=8.2$ and $1.8 \mathrm{~Hz}, \mathrm{H}-6$ '). ${ }^{13} \mathrm{C}(100$ $\left.\mathrm{MHz}, \mathrm{CD}_{3} \mathrm{OD}, \delta\right) 80.0$ (C-2); 67.6 (C-3); 29.4 (C-4); 157.8 (C-5); 96.6 (C-6); 158.1 (C-7); 96.1 (C-8); 157.5 (C-9); 100.3 (C-10); 132.5 (C-1'); 115.5 (C-2'); 146.1* (C-3'); 145.9* (C-4'); 116.1 (C-5'); $119.6(\mathrm{C}-6$ '). *Values may be changed.

Sitosterol-3- $O-\beta$ - $D$-glucopyranoside ${ }^{9,10}$ (3): ${ }^{1} \mathrm{H}$ NMR (200 MHz, $\left.\mathrm{CDCl}_{3}+\mathrm{Py}-\mathrm{d}_{5}, \delta\right): 4.61$ (d, J=7.4 Hz, H-1') and $5.32(\mathrm{H}-6) .{ }^{13} \mathrm{C} \mathrm{NMR}$ $\left(50 \mathrm{MHz}, \mathrm{CDCl}_{3}+\mathrm{Py}-\mathrm{d}_{5}, \delta\right): 39.1$ (C-1); 32.1 (C-2); 78.1 (C-3); 39.9 (C-4); 140.7 (C-5); 121.7 (C-6); 30.0 (C-7); 31.9 (C-8); 50.2 (C-9); 36.8 (C-10); 21.1 (C-11); 37.4 (C-12); 42.4 (C-13); 56.8 (C-14); 23.2 (C-15); 29.9 (C-16); 56.1 (C-17); 12.2 (C-18); 19.2 (C-19); 36.3 (C-20); 19.9 (C-21); 34.1 (C-22); 26.2 (C-23); 46.0 (C-24); 28.4 (C-25); 19.3 (C-26); 18.9 (C-27); 24.4 (C-28); 11.9 (C-29); 102.2 (C-1'); 74.7 (C-2'); 71.4 (C-3'); 71.4 (C-4'); 77.8 (C-5'); 62.6 (C-6').

(+)-Astilbin ${ }^{11}(4):[\alpha]_{\mathrm{D}}=+7.0\left(\mathrm{CH}_{3} \mathrm{OH}, c 0.18\right) .{ }^{1} \mathrm{H}$ NMR $(400$ $\left.\mathrm{MHz}, \mathrm{CD}_{3} \mathrm{OD}, \delta\right): 5.08$ (d, $\left.J=10.6 \mathrm{~Hz}, \mathrm{H}-2\right) ; 4.57$ (d, $\left.J=10.6 \mathrm{~Hz}, \mathrm{H}-3\right)$; 5.92 (d, $J=2.1 \mathrm{~Hz}, \mathrm{H}-6) ; 5.90$ (d, $J=2.1 \mathrm{~Hz}, \mathrm{H}-8) ; 6.95$ (d, $J=1.8 \mathrm{~Hz}$, H-2'); 6.81 (d, $J=8.2 \mathrm{~Hz}, \mathrm{H}-5$ '); 6.84 (dd, $J=1.8$ and $8.2 \mathrm{~Hz}, \mathrm{H}-6$ ');
4.07 (d, J=1.2 Hz, H-1"); 3.55 (m, H-2"); 3.66 (m, H-3"); 3.31 (m, H-4"); 4.23 (m, H-5"); 1.18 (d, J=6.2 Hz, H-6"). ${ }^{13} \mathrm{C}$ NMR (100 $\mathrm{MHz}, \mathrm{CD}_{3} \mathrm{OD}, \delta$ ): 84.1 (C-2); 78.7 (C-3); 196.1 (C-4); 165.7 (C-5); 97.6 (C-6); 168.8 (C-7); 96.4 (C-8); 164.2 (C-9); 102.7 (C-10); 129.4 (C-1'); 115.7 (C-2'); 146.7 (C-3'); 147.5 (C-4'); 116.5 (C-5'); 120.6 (C-6'); 102.3 (C-1"); 71.9 (C-2"); 72.3 (C-3"); 74.0 (C-4”); 70.7 (C-5"); 18.0 (C-6").

$\operatorname{Rutin}^{12}$ (5): ${ }^{1} \mathrm{H}$ NMR (400 MHz, DMSO-d, $\delta$ ): 6.18 (d, $J=1.8$ Hz, H-6); 6.38 (d, J=1.8 Hz, H-8); 7.53 (br. s, H-2'); 6.85 (d, J=8.4 Hz, H-5'); 7.54 (dd, J=8.4 Hz, H-6'); 5.34 (d, J=7.1 Hz, H-1 '); 3.22-3.38 (m, H-2", H-3", H-5", H-2"', H-5"'); 3.04-3.11 (m, H-4", H-4"'); 3.71 (m, H-6"); 3.29 (m, H-6"); 4.40 (br. s, H-1 "');

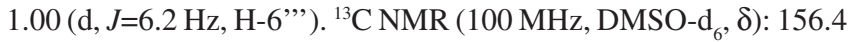
(C-2); 133.3 (C-3); 177.3 (C-4); 161.2 (C-5); 98.8 (C-6); 164.5 (C-7); 93.6 (C-8); 156.5 (C-9); 103.8 (C-10); 121.1 (C-1'); 115.2 (C-2'); 144.8 (C-3'); 148.5 (C-4'); 116.2 (C-5'); 121.6 (C-6'); 101.2 (C-1"); 74.1 (C-2"); 76.5 (C-3"); 70.0 (C-4"); 75.9 (C-5"); 67.0 (C-6"); 100.7 (C-1"'); 70.6 (C-2"”); 70.4 (C-3"'); 71.8 (C-4"'); 68.2 (C-5"'); 17.7 (C-6"').

Quercetin ${ }^{12}$ (6): ${ }^{1} \mathrm{H}$ NMR (400 MHz, DMSO-d $\left.\mathrm{d}_{6}, \delta\right): 6.42$ (d, $J=1.8$ Hz, H-8); 6.20 (d, J=1.8 Hz, H-6); 7.68 (d, J=2.0 Hz, H-2'); 6.89 (d, $J=8,5 \mathrm{~Hz}, \mathrm{H}-5$ '); 7.55 (dd, $J=2.0$ and $8.5 \mathrm{~Hz}, \mathrm{H}-6$ '). ${ }^{13} \mathrm{C}$ NMR $(100$ MHz, DMSO-d, , $\delta$ ): 146.8 (C-2); 135.8 (C-3); 175.9 (C-4); 160.8 (C-5); 98.2 (C-6); 163.9 (C-7); 93.4 (C-8); 156.2 (C-9); 103.0 (C-10); 122.0 (C-1'); 115.1 (C-2'); 145.1 (C-3'); 147.7 (C-4'); 115.6 (C-5'); $120.0\left(\mathrm{C}^{\prime} 6^{\prime}\right)$.

\section{Antioxidant and free radical scavenging assays}

\section{$\beta$-carotene assay}

The experiment with $\beta$-carotene was carried out on TLC plates. After spots developing and plate drying, these were sprayed with a $0.05 \%$ solution of $\beta$-carotene, in $\mathrm{CHCl}_{3}$. Plates were placed under UV $254 \mathrm{~nm}$ light until the background became discolored and spots appeared in orange. ${ }^{5}$

\section{DPPH radical scavenging assay}

Radical scavenging activities of extracts and flavonoids were determined according to the method described by Burda \& Oleszek. ${ }^{6}$ BHT (2,6-di-tert-butyl-4-methylphenol) was used as reference compound. Samples and BHT $(750.0 \mu \mathrm{L})$ were prepared in triplicate for each concentration used $(1.0,10.0$ and $100.0 \mu \mathrm{g} / \mathrm{mL})$ and, to each flask, the volume was adjusted to $2.0 \mathrm{~mL}$ by adding $1.5 \mathrm{~mL}$ of a $0.002 \% \mathrm{p} / \mathrm{v}$ solution of DPPH in methanol. The solutions were shaken vigorously and kept in the dark for $30 \mathrm{~min}$. The control was prepared as above without any extract or substance. Absorbances (measured in a Hitashi 2010 spectrophotometer) were measured at $517 \mathrm{~nm}$ and methanol was used for the baseline correction.

Radical scavenging activity was expressed as the inhibition percentage and was calculated: $\left\{\left(\mathrm{Abs}_{\text {control }}-\mathrm{Abs}_{\text {sample }}\right) / \mathrm{Abs}_{\text {control }}\right\} \mathrm{x}$ 100 where $\mathrm{Abs}_{\text {control }}=$ absorbance of DPPH radical in methanol and $\mathrm{Abs}_{\text {sample }}=$ absorbance of the extracts or pure substances in methanol + DPPH. Scavenging activities were expressed in $\mu \mathrm{g} / \mathrm{mL}$. $\mathrm{IC}_{50}$ values (in $\mu \mathrm{g} / \mathrm{mL}$ ) expressed the concentration of samples necessary to scavenge $50 \%$ of DPPH free radicals.

\section{Artemia salina larvicide bioassay}

Artemia salina encysted eggs $(10 \mathrm{mg})$ were incubated in $100 \mathrm{~mL}$ of seawater artificial light at $28^{\circ} \mathrm{C}, \mathrm{pH} 7-8$. After incubation for $24 \mathrm{~h}$, nauplii were collected with a Pasteur pipete and kept for an additional 
$24 \mathrm{~h}$ under the same conditions to reach the metanauplii stage. The samples (in triplicate) to be assayed were dissolved in DMSO (2 $\mathrm{mg} / 400 \mu \mathrm{L})$ and diluted serially $(10,20,30$ and $50 \mu \mathrm{L} / 5 \mathrm{~mL})$ in seawater. About 10-20 naupli were added to each set of tubes containing the samples. Controls containing $50 \mu \mathrm{L}$ of DMSO in seawater were included in each experiment. Lapachol dissolved in DMSO was used as a positive control. Twenty-four hours later, the number of survivors was counted, recorded and the lethal concentration 50\% and 95\% confidence intervals were calculated by Probitos analysis. ${ }^{7}$

\section{RESULTS AND DISCUSSION}

E. precatoria ethanol extracts of roots and leaf stalks were partitioned with n-butanol and methanol/chloroform, respectively. Both extracts (n-BuOH and LSE-2) underwent, initially, column chromatography over polyamide. The substances were purified over Sephadex LH-20 and identified through ${ }^{1} \mathrm{H}$ and ${ }^{13} \mathrm{C}$ NMR (1D and 2D) spectra. This identification was supported by comparison with authentic samples on TLC, by comparison of spectral data with those reported in the literature and with those obtained from the authentic samples. The structures of isolated compounds are presented in Figure 1. Except for sitosterol-3- $O$ - $\beta$ - $D$-glucopyranoside (3), this is the first description, to the best of our knowledge, of the presence of these compounds in E. precatoria Mart.

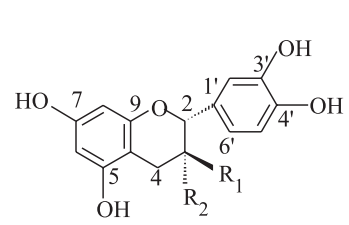

$\mathrm{R}_{1}=\mathrm{OH} \mathrm{R}_{2}=\mathrm{H}(+)$-catechin $(\mathbf{1})$

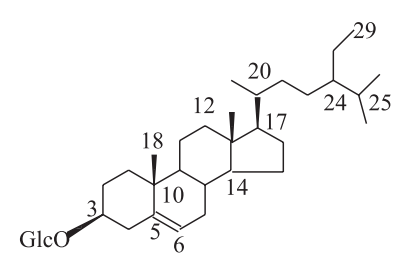

$\mathrm{R}_{1}=\mathrm{H} \mathrm{R}_{2}=\mathrm{OH}(-)$-epicatechin (2) sitosterol-3-O- $\beta$ - $D$-glucopyranoside (3)
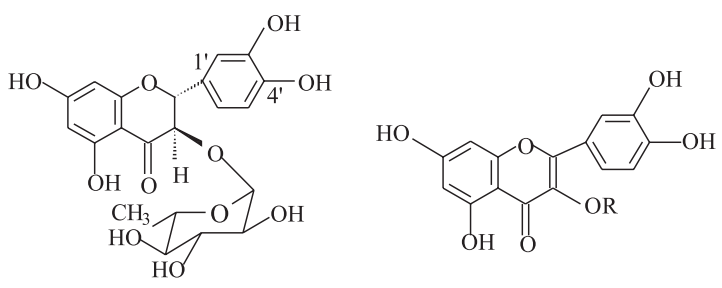

Astilbin (4)

$$
\mathrm{R}=3 \text {-OGlc }(6 " \longrightarrow \text { 1"')rha, rutin (5) }
$$

$\mathrm{R}=\mathrm{H}$ quercetin $(6)$

Figure 1. Structures of compounds isolated from roots and leaf stalks ethanol extracts of E. precatoria

Antioxidative and radical scavenging properties of extracts and flavonoids were evaluated using $\beta$-carotene bleaching method by $\mathrm{TLC}^{5}$ and 1,1-diphenyl-2-picrylhydrazyl (DPPH) radical. ${ }^{6}$ In the first method, the antioxidant activity is measured by the ability of a compound to inhibit the oxidation of $\beta$-carotene, by maintaining the orange color in the plates. ${ }^{5}$ The DPPH is a purple stable organic radical with an absorption band in the range of 515-528 nm; when the radical accept an electron or a free radical species, the result is a visually noticeable discoloration from purple to yellow. Because the DPPH radical can accommodate many samples in a short period of time and is sensitive enough to detect active molecules at low concentrations, it has been extensively used to screen antiradical activities of vegetal extracts, juices and fruits. ${ }^{13}$

All extracts and flavonoids from $E$. precatoria were active in the $\beta$-carotene bleaching method. DPPH radical scavenging activities for extracts, flavonoids and BHT (reference compound) are showed in Figure 2. At $100.0 \mu \mathrm{g} / \mathrm{mL}$, all extracts and pure compounds presented high radical scavenging activity. BHT, catechin (1), epicatechin (2), n$\mathrm{BuOH}$ and LSE-2 extracts showed the higher activities at $1.0 \mu \mathrm{g} / \mathrm{mL}$. IC values are listed in Table 1 and the observed scavenging activity declines in the order: LSE-2 > quercetin $>$ catechin $=$ epicatechin $>$ n-BuOH $>$ rutin $>$ BHT $=$ astilbin $>$ LSE $>$ ERE. BHT was only more active than astilbin, the less active flavonoid. These results are in agreement with Burda \& Oleski, ${ }^{6}$ who demonstrated that flavonoids as quercetin, having the orto-di-hydroxy system in ring B, a double bond between C-2 and $\mathrm{C}-3$ in ring $\mathrm{C}$ and a free hydroxy groups at $\mathrm{C}-3$ (ring $\mathrm{C}$ ) and $\mathrm{C}-5$ (ring A) presented the higher antioxidant activity. Also, according to these authors, the presence of a sugar in the flavonoid structure resulted in a diminution of the antioxidant activity. Then, the absence of the C2-C3 double bond in astilbin and a glycoside in astilbin and rutin explains their smaller activities. LSE-2 extract showed the biggest activity among all samples tested. A synergistic effect due to the other phenolic substances present in this extract can explain this result. According to Hsu et al. ${ }^{13}$ the combination of different compounds at a certain effective dosage can strengthen or weaken their scavenging free radicals. Such synergistic effects were detected in different antioxidants including tocopherol, ascorbic acid flavonoids and herbal medicines. The unusually high potency of the root and leaf stalks extracts and fractions of $E$. precatoria in free radical scavenging is shared by few other plants ${ }^{14}$ and several studies have shown that hepatoprotective effects are associated with antioxidant rich extracts. ${ }^{14} \mathrm{Hsu}$ and cols. ${ }^{13}$ have described the activity of flavonoids, such as quercetin, rutin and catechin, to prevent inflammation. Thus, the potency of the E. precatoria extracts in free radical scavenging activity, which may be associated with the isolated flavonoids, could provide a scientific basis for the health benefits claimed for roots of this plant in folk medicine and warrant further studies to assess the potential of this plant as effective natural remedies.

The antioxidant activity of (+)-catechin and (-)-epicatechin, quercetin and rutin are already reported in literature. ${ }^{6,15}$ The antioxidant activities of the extracts of E. precatoria and of astilbin are reported here for the first time, to the best of our knowledge.

The brine shrimp (Artemia salina) lethality bioassay is an efficient, rapid and inexpensive test that has a good correlation with

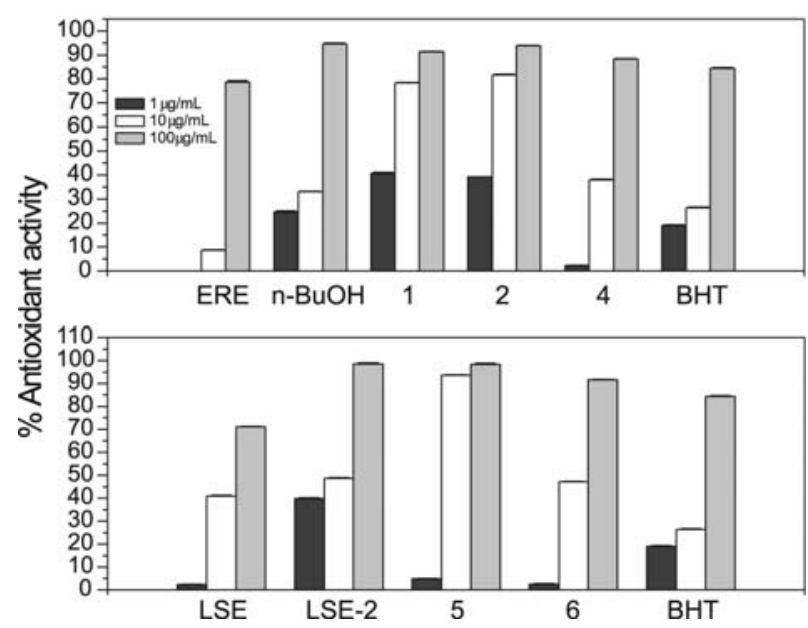

Figure 2. DPPH radical scavenging activity of extracts ERE (root ethanol extract), $n-\mathrm{BuOH}$ (n-butanol extract from ERE), LSE (leaf stalk ethanol extract) and LSE-2 (LSE soluble fraction obtained by treatment with methanol/ chloroform 1:1) and flavonoids from E. precatoria Mart. and BHT, in three different concentrations 
Table 1. $\mathrm{IC}_{50}$ values on DPPH scavenging activity and $\mathrm{LC}_{50}$ cytotoxic activity, on brine shrimp (A. salina) lethality test of extracts, flavonoids of $E$. precatoria (Mart.) and reference compounds

\begin{tabular}{lcc}
\hline $\begin{array}{l}\text { Extracts and } \\
\text { substances }\end{array}$ & $\mathrm{IC}_{50}(\mu \mathrm{g} / \mathrm{mL})^{\mathrm{a}}$ & $\mathrm{LC}_{50}(\mu \mathrm{g} / \mathrm{mL})^{\mathrm{b}}$ \\
\hline ERE & $43.54 \pm 5.60$ & $1010.0(342.05-1186.65)$ \\
n-BuOH & $8.83 \pm 5.55$ & $481.0(154.58-898.75)$ \\
(+)-Catechin & $5,15 \pm 2.42$ & --- \\
$(-)$-Epicatechin & $5,19 \pm 2.89$ & --- \\
(+)-Astilbin & $16.56 \pm 2.66$ & --- \\
LSE & $24.74 \pm 11.72$ & $523.0(84.85-977.59)$ \\
LSE-2 & $3.33 \pm 4.11$ & $271.0(111.73-658.11)$ \\
Rutin & $12.44 \pm 1.99$ & --- \\
Quercetin & $3.73 \pm 1.31$ & --- \\
BHT & $16.36 \pm 3.63$ & --- \\
Lapachol $^{\mathrm{c}}$ & -- & $68.0(57.10-79.05)$ \\
\hline
\end{tabular}

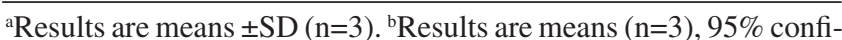
dence limits in parentheses. 'Reference standard. Extracts ERE: root ethanol extract. n-BuOH: n-butanol extract from ERE. LSE: leaf stalk ethanol extract. LSE-2: LSE soluble fraction obtained by treatment with methanol/chloroform 1:1.

cytotoxic activity in some human solid tumors and with pesticidal activity. ${ }^{5}$ The cytotoxic effect of roots and leaf stalks extracts and flavonoids of $E$. precatoria was evaluated (Table 1).

LSE-2 was twice more cytotoxic than $\mathrm{n}-\mathrm{BuOH}$ extract, due probably to the presence of quercetin, that inhibit the growth of cells from various human cancers. ${ }^{16}$ The toxicity showed by the $\mathrm{n}-\mathrm{BuOH}$ extract can be associated with catechin, whose activity is reported in the literature. ${ }^{17}$ Astilbin was not tested here due the little amount isolated.

Sitosterol-3-O- $\beta-D$-glucopyranoside (3) gave $70 \%$ protection in an antilethal evaluation test on venon of Bothrops jararaca snake on albino mice. ${ }^{18}$ As already previously reported, ${ }^{4}$ the presence of this steroid glucoside, together with $\beta$-sitosterol in roots extract of E. precatoria can justify the anti-snake bite activity presented by the decoctions of this part of the plant.

\section{ACKNOWLEDGEMENT}

The authors thank Conselho Nacional de Desenvolvimento Científico e Tecnológico (CNPq) for L. A. R. dos S. Lima and M. A. D. Boaventura grants and Coordenação de Aperfeiçoamento do Pessoal de Nivel Superior (CAPES) for A. L. Q. de A. Galotta grant.

\section{REFERENCES}

1. Bourdy, G.; Dewalt, S. J.; Chávez de Michel, L. R.; Roca, A.; Deharo, E.; Muñoz, V.; Balderrama, L.; Quenevo, C.; Gimenez, A.; J. Ethnopharmacol. 2000, 70, 87.

2. Deharo, E.; Baelmans, R.; Gimenez, A.; Quenevo, C.; Bourdy, G.; Phytomedicine 2004, 11, 516 .

3. Jensen, J. F.; Kvist, L. P.; Christensen, S. B.; J. Nat. Prod. 2002, 65, 1915.

4. Galotta, A. L. Q. A.; Boaventura, M. A. D.; Quim. Nova 2005, 28, 610.

5. Cavin, A; Potterat, O.; Wolfender, J.-L.; Hostettmann, K.; Dyatmyko, W.; J. Nat. Prod. 1998, 61, 1497.

6. Burda, S.; Oleszek, W.; J. Agric. Food Chem. 2001, 49, 2774.

7. Pimenta, L. P. S.; Pinto, G. B.; Takahashi, J. A.; Silva, L. G. F.; Boaventura, M. A. D.; Phytomedicine 2003, 10, 209.

8. Foo, L.-Y; Lu, Y.; McNabb, W. C.; Waghor, G.; Ulyatt, M. J.; Phytochemistry 1997, 45, 1689.

9. Ramaiah, P. A.; Lavie, D.; Budhiraja, R. D.; Sudhir, S.; Garg, K. N.; Phytochemistry 1984, 23, 143.

10. Fang, J-M.; Wang, K-C.; Cheng, Y-S.; Phytochemistry 1991, 30, 3383.

11. Du, Q.; Li, L.; Jerz, G.; J. Chromatogr., A 2005, 1077, 98.

12. Agrawal, P. K.; Carbon-13 of flavonoids, Elsevier Science Publisher: Amsterdam, 1989.

13. Hsu, F.-H.; Houng, J.-Y.; Chang, C.-L.; Wu, C.-C.; Chang, F.-R.; Wu, Y.-C.; J. Agric. Food Chem. 2005, 53, 6117.

14. Harish, R.; Shivanandappa, T.; Food Chem. 2006, 95, 180.

15. Luo, X.-D.; Basile, M. J.; Kennelly, E. J.; J. Agric. Food Chem. 2002, $50,1379$.

16. Jagadeeswaran, R.; Thirunavukkarasu, C.; Gunasekaran, P.; Ramamurty, N.; Sakthisekaran, D.; Fitoterapia 2000, 71, 395.

17. Wanjala, C. C. W.; Maijinda, R. R. T.; Fitoterapia 2001, 72, 649.

18. Mors, W. B.; Nascimento, M. C.; Pereira, B. M. R.; Pereira, N. A.; Phytochemistry 2000, 55, 627. 